\title{
SYNTHESIS OF A LAMELLAR MESOSTRUCTURED ALUMINOPHOSPHATE
}

\author{
TATSUO KIMURA, YOSHIYUKI SUGAHARA and KAZUYUKI KURODA \\ Department of Applied Chemistry \\ Waseda University \\ Ohkubo, Shinjuku-ku, Tokyo 169, Japan
}

\begin{abstract}
A lamellar mesostructured hexadecyltrimethylammonium (C16TMA)aluminophosphate material was hydrothermally prepared from the mixture of $\mathrm{Al}\left(\mathrm{O}^{\mathrm{i}} \mathrm{C}_{3} \mathrm{H}_{7}\right)_{3}, 85 \% \mathrm{H}_{3} \mathrm{PO}_{4}, \mathrm{C}_{16} \mathrm{TMACl},\left(\mathrm{CH}_{3}\right)_{4} \mathrm{NOH}, \mathrm{CH}_{3} \mathrm{OH}$, and $\mathrm{H}_{2} \mathrm{O}$. The XRD pattern of the as-synthesized product indicated that the product had a layered structure, and the SEM and TEM images also supported this result. The ${ }^{27} \mathrm{Al} \mathrm{MAS}$ NMR spectrum of the product showed the presence of 4-coordinated Al composed of $\mathrm{Al}(\mathrm{OP}) 4$, and the ${ }^{31} \mathrm{P}$ MAS NMR spectra showed the presence of 4-coordinated $\mathrm{P}$ composed of $\mathrm{O}-\mathrm{P}(\mathrm{OAl}) 3$, including $\mathrm{HO}-\mathrm{P}(\mathrm{OAl}) 3$. Judging from the composition of the product measured by chemical analysis $\left(1.4 \mathrm{C}_{16} \mathrm{TMA} \cdot \mathrm{Al}_{3} \mathrm{P}_{4} \mathrm{O}_{16} \bullet \mathrm{xH}_{2} \mathrm{O}\right)$, 4coordinated $\mathrm{P}$ atoms were composed of $\mathrm{HO}-\mathrm{P}(\mathrm{OAl}) 3$ and $\mathrm{C} 16 \mathrm{TMAO}-\mathrm{P}(\mathrm{OAl}) 3$.
\end{abstract}

\section{INTRODUCTION}

Since the role of surfactants for the preparation of mesoporous materials was disclosed, ${ }^{1}$ silica-based mesoporous molecular sieves and inorganic-organic mesostructured materials have recently been investigated. However, there have been only several reports on mesostructured surfactant-aluminophosphates, ${ }^{2-8}$ and no reports on mesoporous aluminophosphates, although AlPO4-n and SAPO-n molecular sieves are well known. ${ }^{9-10}$ Since the tetrahedral networks can be constructed by utilizing both $\mathrm{AlO}_{4}$ and $\mathrm{PO}_{4}$ units, it is quite reasonable to attempt to prepare a variety of mesophase materials composed of aluminophosphate networks. Previously reported mesostructured aluminophosphates have layered structures, ${ }^{2-8}$ whereas we have succeeded in synthesizing hexagonal mesostructured aluminophosphates by modifying the synthetic conditions reported by C. A Fyfe et al. ${ }^{11}$ Based on our research on the hexagonal mesophases, we have noticed that lamellar and hexagonal mesophases form in very closely interrelated synthetic conditions. Therefore, it is necessary to examine the formation conditions of lamellar mesostructured aluminophosphates in more detail. Thus, a lamellar mesostructured alkyltrimethylammonium-aluminophosphate was synthesized hydrothermally and characterized in order to elucidate the feature of the lamellar mesophases. 


\section{EXPERIMENTAL PROCEDURE}

The synthesis procedure was followed by a report of C. A Fyfe et al., ${ }^{8}$ although methanol was added to the starting mixture as cosolvent. Hexadecyltrimethylammonium (C16TMA) chloride, tetramethylammonium hydroxide (TMAOH, 10wt\% in methanol), 85\% phosphoric acid, and water were mixed for a few minutes. Aluminum triisopropoxide was added to this solution under vigorous stirring, and the reaction mixture was stirred for $24 \mathrm{hr}$. The molar ratio of the starting gel was $0.3 \mathrm{Al}_{2} \mathrm{O}_{3} \cdot \mathrm{P}_{2} \mathrm{O}_{5} \cdot$ $\mathrm{C}_{16 \mathrm{TMA}} \cdot 1.6 \mathrm{TMAOH} \cdot 15 \mathrm{H}_{2} \mathrm{O} \cdot 40.9 \mathrm{CH}_{3} \mathrm{OH}$. This starting gel was hydrothermally treated at $130^{\circ} \mathrm{C}$ for $120 \mathrm{hr}$. The resultant product was washed repeatedly with distilled water, and dried. The resultant inorganic-organic mesophase material was analyzed by powder XRD, ${ }^{27} \mathrm{Al}$ MAS NMR, ${ }^{31} \mathrm{P}$ MAS NMR, SEM, TEM, and chemical analysis.

\section{RESULTS AND DISCUSSION}

The XRD pattern of the as-synthesized product is shown in Fig. 1. The main peak at d-spacing of $3.29 \mathrm{~nm}$ and the peaks of higher order reflections were observed, indicating that this product had a layered structure, which is consistent with a report of C. A Fyfe et al. ${ }^{8}$ The SEM image shown in Fig. 2 indicates this product obviously has platy crystals. The TEM image shown in Fig. 3 also exhibits the layered nature of the product.

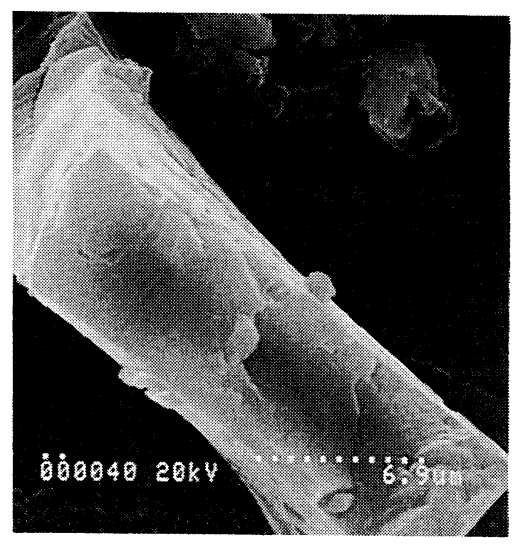

FIGURE 2. Scanning erectron micrograph of the product.

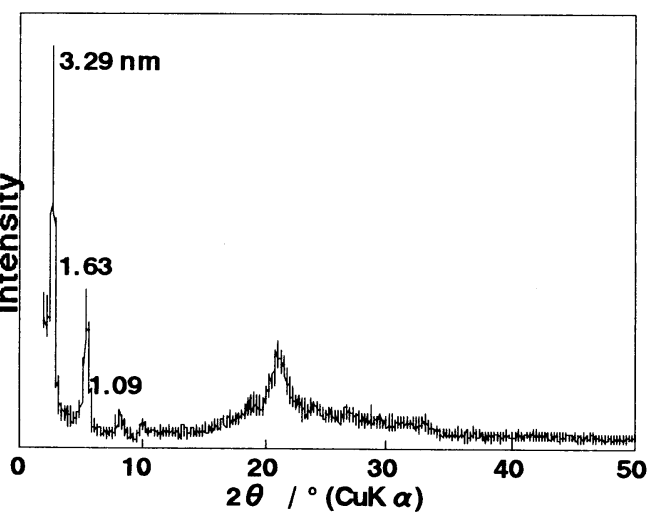

FIGURE 1. XRD pattern of the as-synthesized product.

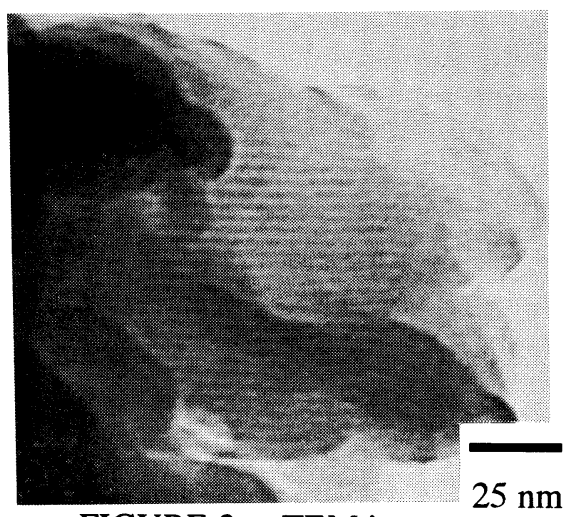

FIGURE 3. TEM image of the product. 
Figures 4 and 5 show the ${ }^{27} \mathrm{Al}$ MAS NMR and ${ }^{31} \mathrm{P}$ MAS NMR spectra, respectively. As to the environment of $\mathrm{Al}$ atoms, the chemical shift of $42.0 \mathrm{ppm}$ indicates the presence of tetrahedral $\mathrm{Al}$ sites composed of $\mathrm{Al}(\mathrm{OP}) 4$. For $\mathrm{P}$ atoms, the ${ }^{31} \mathrm{P} \mathrm{CP}$ MAS NMR spectrum shows two signals at -17.8 and $-20.2 \mathrm{ppm}$, indicating the presence of tetrahedral $\mathrm{P}$ sites composed of $\mathrm{OP}(\mathrm{OAl}) 3 .{ }^{10} \mathrm{~A}$ signal at $-20.2 \mathrm{ppm}$ is assignable to HO$\mathrm{P}(\mathrm{OAl}) 3$, because this signal remarkably decreased in the ${ }^{31} \mathrm{P}$ MAS NMR spectrum. Judging from the composition of the product measured by chemical analysis (1.4C16 TMA $\left.-\mathrm{Al}_{3} \mathrm{P}_{4} \mathrm{O}_{16} \bullet \mathrm{xH}_{2} \mathrm{O}\right)$, a signal at $-17.8 \mathrm{ppm}$ would be assignable to C16TMAO-P(OAl)3.

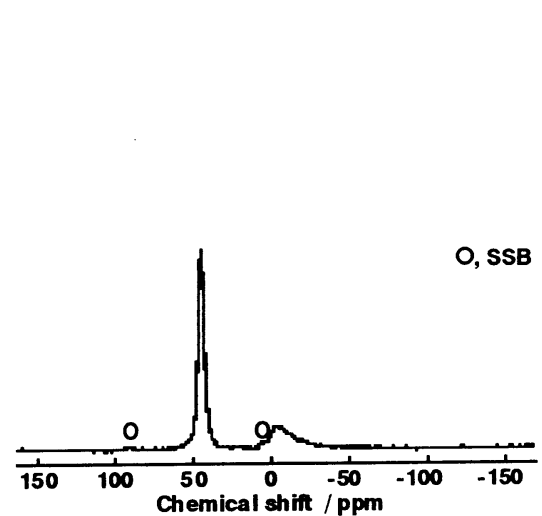

FIGURE 4. ${ }^{27} \mathrm{Al}$ MAS NMR spectrum of the product.

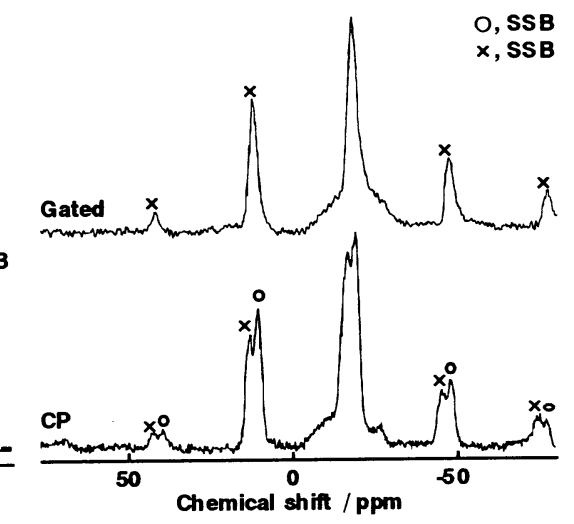

FIGURE 5. 31P MAS NMR spectra of the product.

With the increase in the concentration of C16TMA ions, no ordered structures were observed. While, AlPO4-20 coexisted with a lamellar masophase when very low amount of C16TMA was employed. Although the addition of methanol as cosolvent to the reaction system leads the variation of surfactant assemblies, the as-synthesized product had a lamellar structure, being in agreement with a report of C. A. Fyfe et al. who used the same starting mixture except methanol. ${ }^{8}$ They have reported the formation of lamellar mesophases under the conditions with a small amount of water. Besides, we found that lamellar mesostructured aluminophosphates were obtained under the conditions with a large amount of water. ${ }^{11}$ Based on these results, (Al+P)/C16TMA ratio rather than C16TMA concentration influences the structure of mesophases. On the other hand, a possible amount of remaining TMA ions in the product is very low based on the CHN analysis. However, TMAOH may act as an basic source, not only because no layered aluminophosphates were obtained under TMAOH free conditions, but also because a layered aluminophosphate was obtained under the conditions without TMAOH when $\mathrm{C} 16 \mathrm{TMACl} / \mathrm{OH}$ was used instead of $\mathrm{C} 16 \mathrm{TMACl}$. 


\section{CONCLUSIONS}

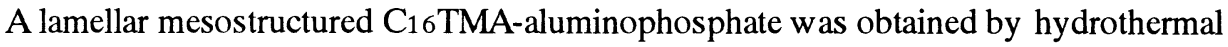
synthesis from the mixture of $\mathrm{Al}\left(\mathrm{O}^{\mathrm{i}} \mathrm{C}_{3} \mathrm{H}_{7}\right)_{3}, 85 \% \mathrm{H}_{3} \mathrm{PO}_{4}, \mathrm{C}_{16 \mathrm{TMACl}},\left(\mathrm{CH}_{3}\right)_{4} \mathrm{NOH}$, $\mathrm{CH}_{3} \mathrm{OH}$, and $\mathrm{H}_{2} \mathrm{O}$. The composition of the aluminophosphate layers was thought to be $\mathrm{Al}_{3} \mathrm{P}_{4} \mathrm{O}_{16}$, being constructed of $\mathrm{Al}(\mathrm{OP})_{4}, \mathrm{HO}-\mathrm{P}(\mathrm{OAl}) 3$, and $\mathrm{C}_{16} \mathrm{TMAO}-\mathrm{P}(\mathrm{OAl}) 3$. The structure of the mesophases of the $\mathrm{C} 16 \mathrm{TMA}$-aluminophosphates was influenced by several interrelated parameters such as $\mathrm{Al} / \mathrm{P}$ ratios, $(\mathrm{Al}+\mathrm{P}) / \mathrm{C} 16 \mathrm{TMA}$ ratios, C16TMA concentrations, and so on.

\section{ACKNOWLEDGMENT}

K.K. acknowledges the financial assistance from the Grant in Aid for the Scientific Research by the Ministry of Education, Science, and Culture.

\section{REFERENCES}

1 T. Yanagisawa, T. Shimizu, K. Kuroda, and C. Kato, Bull. Chem. Soc. Jpn., 63, 988 (1990).

2 S. Oliver, A. Kuperman, N. Coombs, A. Lough, and G. A. Ozin, Nature, 378, 47 (1995).

3 S. Oliver, N. Coombs, G. A. Ozin, Adv. Mater., 7, 931 (1995).

4 G. A. Ozin and S. Oliver, Adv. Mater., 7, 943 (1995).

5 A. Chenite, Y. L. Page, V. R. Karra, and A. Sayari, Chem. Commun., 411 (1996).

6 A. Sayari, V. R. Karra, J. S. Reddy, and I. L. Moudrakovski, Chem. Commun., 413 (1996).

7 A. Sayari, I. Moudrakovski, and J. S. Reddy, Chem. Mater., 8, 2080 (1996).

8 C. A. Fyfe, W. Schwieger, G. Fu, G. T. Kokotailo, H. Grondey, Symposium on Zeolites, Layered Compounds and Other Microporous Solids, 209th National Meeting, Am. Chem. Soc. Anaheim, CA, April 2-7, 266 (1995).

9 S. T. Wilson, B. M. Lok, C. A. Messina, T. R. Cannan, and E. M. Flanigen, J. Am. Chem. Soc., 104, 1146 (1982).

10 B. M. Lok, C. A. Messina, R. L. Patton, R. T. Gajek, T. R. Cannan, and E. M. Flanigen, J. Am. Chem. Soc., 106, 6092 (1984).

11 T. Kimura, Y. Sugahara and K. Kuroda, Book of Abstracts, 11th International Zeolite Conference, August 12-17, RP 45 (1996).

12 R. F. Mortlock, A. T. Bell, and C. J. Radke, J. Phys. Chem., 97, 767 (1993). 